\title{
Clinical, Histological, and Scintigraphic Comparative Study of the Use of Mandibular Bone Marrow and Peripheral Blood in Bone Neoformation
}

\author{
Paulo José Pasquali $\mathbb{D}^{1,2}$ Rodrigo André Dall'Agnol, ${ }^{3}$ Lucas Garcia Rezende, ${ }^{4}$ \\ and Elizabeth Ferreira Martinez ${ }_{(D)}^{5}$ \\ ${ }^{1}$ Division of Implantology, Santa Mônica Hospital Center, Erechim, RS, Brazil \\ ${ }^{2}$ Division of Implantology, Faculdade São Leopoldo Mandic, Campinas, Brazil \\ ${ }^{3}$ Division of Orthopedics and Traumatology, Saint Hill Hospital, Caçador, SC, Brazil \\ ${ }^{4}$ Division of Nuclear Medicine, Ernesto Dornelles Hospital, Porto Alegre, RS, Brazil \\ ${ }^{5}$ Division of Oral Pathology and Cell Biology, São Leopoldo Mandic Research Institute, Campinas, SP, Brazil
}

Correspondence should be addressed to Paulo José Pasquali; paulo@paulopasquali.com.br

Received 20 August 2021; Revised 8 November 2021; Accepted 13 December 2021; Published 31 December 2021

Academic Editor: Halim Issever

Copyright (c) 2021 Paulo José Pasquali et al. This is an open access article distributed under the Creative Commons Attribution License, which permits unrestricted use, distribution, and reproduction in any medium, provided the original work is properly cited.

\begin{abstract}
Background and Purpose. To evaluate the capacity of mandibular bone marrow blood aspirate associated with biomaterials to stimulate bone tissue neoformation compared to the use of peripheral blood aspirate in patients with bone loss in the premaxillary region. Materials and Methods. The study included 16 patients with maxillary atresia. The region was grafted with xenograft blocks associated with the following treatments: G1, the patient's peripheral blood during surgery, and G2, dripping of mandibular bone marrow blood until the xenograft was completely wet. After 7 and 14 days, scintigraphic images of the regions of interest (ROI) were taken to quantify pixels, which indicate osteogenic activity. Additionally, trephined samples obtained at the time of implant placement were stained in $\mathrm{H} \& \mathrm{E}$, and newly formed bone tissue was quantified. The data were tabulated and statistically analyzed at a significance level of 5\%. Results. Scintigraphic data showed greater osteogenic activity with mandibular bone marrow blood (G2) at all times evaluated $(p<0.05)$. As for the histomorphometric analysis, a greater amount of bone tissue was observed in samples treated with mandibular bone marrow blood (G2) compared to peripheral blood (G1) $(p<0.05)$. Conclusions. The appositional bone reconstruction technique in the block associated with mandibular bone marrow blood increased bone neoformation and osteogenic activity compared to conventional graft treatment with peripheral blood.
\end{abstract}

\section{Introduction}

Although the autologous bone graft obtained from the intraoral region is a safe option to restore bone volume, it presents undesirable postsurgical comorbidities [1]. Thus, the use of biomaterials has been widely used as an alternative to autologous grafts [2].

However, bone substitutes have deficient osteogenic and osteoinductive capacities, which can affect the success of the procedure [3]. The lack of cellularity observed in bone substitutes has been arousing interest in tissue engineering research, which aims at associating osteogenic autologous cells with osteoconductive biomaterials. In this context, bone marrow represents a promising source of autologous cells, containing a vast cellular component $[4,5]$, which combined with the angiogenic potential [6] improves tissue regeneration and graft integration [7].

Autologous bone marrow concentrate has known benefits due to the wide variety of cells, including endothelial progenitor cells, mesenchymal stem cells (MSCs), hematopoietic stem cells (HSCs), and other progenitor cells. In addition to the cellular component, it contains growth factors and chemokines, including platelet-derived growth factor, bone morphogenetic protein, transforming growth 
factor-beta, vascular endothelial growth factor, interleukin (IL)-8, and IL-1 receptor antagonist [8-11]. In addition, bone marrow aspiration to collect cells is relatively easier than using autologous bone graft from the same donor site, making it a very versatile source [12].

Of the cellular bone marrow components, there has been a greater interest in the use of stem cells for bone regeneration, since in vitro and in vivo studies have shown highly promising results $[13,14]$. In addition to originating blood cells, bone marrow may have the potential to induce undifferentiated cells to differentiate into a variety of tissues, including the bone and cartilage [15].

In this context, studies aiming to search for bone donor sites with less comorbidities for bone grafting have been disseminated in recent times, with emphasis on the use of mandibular bone marrow blood. Collecting mandibular bone marrow blood for intraoral bone grafts is easier as it comes from a site that is being manipulated in the transsurgical period [16]. Furthermore, it has stem cells with a high capacity for osteogenic differentiation, being considered an important enhancer in osteogenic grafts [17].

In addition to the cellular potential, it has the capacity to promote vascularization through the use of mandibular bone marrow blood, which, combined with the use of biomaterials with good osteogenic potential, can improve surgical bed repair [18].

Thus, the objective of this study was to evaluate the capacity of mandibular bone marrow blood aspirate associated with biomaterials to stimulate bone tissue neoformation compared to the use of peripheral blood aspirate in patients with bone loss in the premaxillary region.

\section{Methods}

2.1. Study Design. The current study was designed as a double-blind, randomized, parallel arms controlled clinical trial study with the aim of evaluating the clinical, scintigraphic, and histological results of blood aspirate from mandibular bone marrow compared to peripheral blood in patients with atresia in the premaxillary region. The study was approved by the Research Ethics Committee (IRB-\# 2,540,760) of the São Leopoldo Mandic Dental Research Institute and Center (Campinas, SP, Brazil). Prior to participation, all patients were individually informed about the nature and risks and benefits of the proposed study and signed an informed consent form.

2.2. Population Screening. A total of 16 patients ( 8 women and 8 men, average age of $50.56 \pm 5.12$ years old) were recruited in the present study. The inclusion criteria were edentulous patients in the premaxillary region, anterior alveolar ridge with a buccolingual thickness of 2-3 $\mathrm{mm}$, need for rehabilitation with osseointegrated implants in the anterior maxillary region, and being aged between 40 and 60 years. The exclusion criteria were the history of neoplastic disease treated with radio or chemotherapy, pregnant or nursing patients, use of medication that changes the bone metabolism, smokers, and diabetic patients.
2.3. Randomization and Power Calculation. The sample size was based on previous studies [14, 19, 20], in which power calculation was performed using a statistical software, establishing that 16 patients should be included to reach $80 \%$ of power in detecting bone formation level differences between groups.

The patients were randomly divided with a $1: 1$ allocation ratio into the following two groups. Group 1 (G1), with only xenogenic bone blocks associated with peripheral blood and grafting in hemipremaxilla $(n=16)$. Group 2 (G2), with mandibular bone marrow blood associated with the same biomaterial $(n=16)$ on the contralateral side. As the study had a split mouth design, all patients received both treatments. The hemipremaxilla receiving each treatment was assigned randomly using the website Randomization.com (http://www.randomization.com), and the randomization was placed in an opaque envelope. All patients were enrolled and equally prepared for the surgical procedure at the same section by a single investigator (PJP). The procedures were only revealed to the surgeon immediately before the surgery.

2.4. Blinding. Study participants were blinded to the treatment received. Blinding of the investigator was applicable until the surgery section. Participants' identity and their corresponding study group were concealed by assigning an identification number to all laboratory specimens.

2.5. Surgical Procedure. Before the surgical procedure, each patient was prepared with intraoral mouthwash and perioral skin asepsis using $0.12 \%$ and $2 \%$ chlorhexidine, respectively. After placing sterile drapes, topical anesthesia with xylocaine was administered in the region to be surgically accessed, followed by infiltrative anesthesia and regional blockade with $1: 100,000$ mepivacaine and epinephrine association. Then, an incision was made in the crest of the alveolar ridge between the canine regions. A full-thickness flap was detached in the premaxilla with periosteum detachers, and the remaining bone structure was removed with number 2 spherical carbide drills in order to expose maxillary bone marrow and maximize graft irrigation. Subsequently, xenogenic blocks of bovine origin (Bonefill ${ }^{\circledR}$, Bionnovation, Bauru, SP, Brazil) measuring $20 \times 20 \times 5 \mathrm{~cm}$ were sculpted with diamond disks and carbide drills to adapt them to the remaining bone base.

2.6. Mandibular Bone Marrow Blood Aspirate and Peripheral Blood Collection. In the same surgical procedure, the patient was anesthetized in the mandibular region, and $1 \mathrm{~mL}$ of blood was collected from the mandibular bone marrow region. Cone beam computed tomography was used to choose a wide and easily accessible bone marrow chamber. A $22 \mathrm{~mm}$ long steel drill with $2.3 \mathrm{~mm}$ diameter was used. This drill has a mobile metal ring in its composition that can be fixed to obtain a stop of safe depth, with a sharp active tip at the end to penetrate the cortical bone. A $10 \mathrm{~mL}$ hypodermic disposable syringe (BD) [21] adapted to a sterilizable metal 
cannula (ICE SP, Brazil) of $2 \mathrm{~mm}$ diameter previously heparinized was used to access the bone marrow chamber of the mandible and collect mandibular bone marrow blood.

For the peripheral blood sampling, a venipuncture was performed in the superficial veins of the anterior surface of the upper extremity. A tourniquet 3-4 inches above the selected puncture site was applied. The blood collection was accomplished using 22-gauge needles and $5 \mathrm{~mL}$ syringes without any additive (BD ${ }^{\circledR}$, USA).

According to the groups evaluated, the sculpted blocks were filled with peripheral blood during surgery (G1) or dripped with mandibular bone marrow blood until the xenograft was completely wet (G2). After adaptation, the blocks were fixed to the bone defect with one or two titanium screws (Neodent, Curitiba, PR, Brazil) with $1.5 \mathrm{~mm}$ in diameter and $8.0-10.0 \mathrm{~mm}$ in length. After block fixation, a hydrogel membrane (Biocelltis, Florianópolis, SC, Brazil) was used to isolate the xenograft in both groups. Next, the wound was sutured with nylon 5 thread (Technofio, Goiânia, GO, Brazil).

2.7. Bone Scintigraphy. On days 7 and 14 after grafting, bone scintigraphy was performed to comparatively analyze osteogenic cell activity in the grafted area in the groups [22-24] (Figure 1).

The scintigraphy device used was a single-headed Symbia E (Siemen, Germany). The test was performed through intravenous administration of the radiopharmaceutical methylene diphosphonate (MDP) labeled with technetium- $99 \mathrm{~m}$ $(99 \mathrm{mTc})$, with the mean dose administered being $26-30 \mathrm{mCi}$, calculated according to the patient's weight. MDP is a drug with tropism for organic bone matrix which concentrates in greater quantity with greater osteogenesis [25-27]. O 99mTc is a radioisotope that emits pure gamma radiation, with $140 \mathrm{Kev}$ of energy and physical half-life of six hours.

The test was performed at the Nuclear Medicine Center of Santa Mônica Hospital (Erechim, RS, Brazil). The images obtained were evaluated considering the number of pixels in the region of interest (ROI).

The optical density of the ROI was evaluated using the e.soft syngo ${ }^{\circledR}$ analysis program (Siemens, USA).

2.8. Histological and Histomorphometric Analyses. The implants were installed 4 months after grafting. Tissue samples were collected using a trephine drill of $2.3 \mathrm{~mm}$ diameter in the axial direction of the implant installation site, up to a height of the remaining bone base. After sample collection, the implants (Bone Level Tapered, BLT, Straumann, Basileia, Switzerland) were installed sequentially in the following dimensions ( $3.3 \mathrm{~mm}$ diameter X $10.0 \mathrm{~mm}$ length).

The collected samples were stored in $10 \%$ buffered formalin ( $\mathrm{pH}$ 7.2) and sent for histological evaluation at the Laboratory of Anatomical Pathology of Faculdade São Leopoldo Mandic (Campinas, SP, Brazil). Then, the samples were demineralized with $20 \%$ formic acid, embedded in histological paraffin, and stained with hematoxylin and eosin. Later, the slides were mounted with biological resin (Permount ${ }^{\circledR}$, Fisher Scientific, NJ, USA).

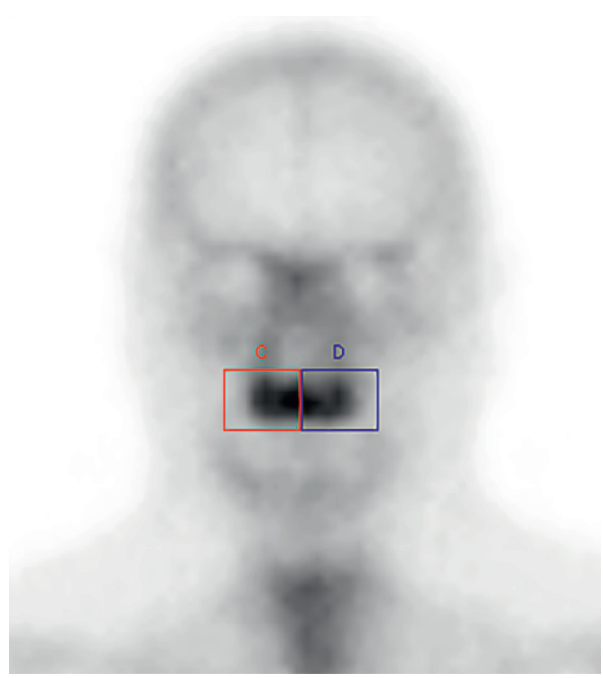

FIGURE 1: Representative image pixel measurement in the ROI.

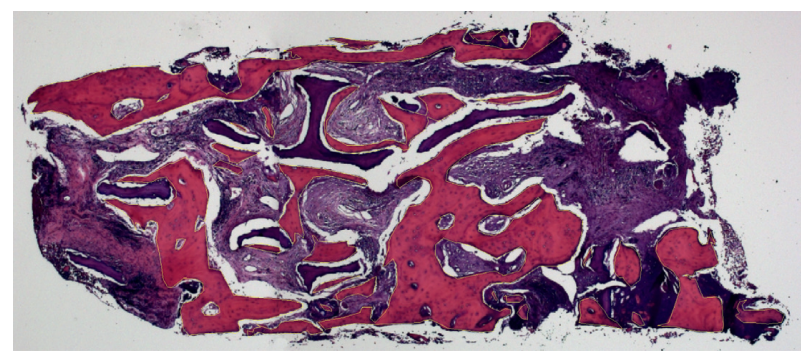

FIGURE 2: Histological image stained with hematoxylin and eosin showing the measured areas in the trephine, in yellow.

Histomorphometry of the slides was performed from images captured in a computerized imaging system (AxioVision Rel 4.8, Carl Zeiss, Oberkochen, Germany) coupled to the Axioskop 2 plus optical light microscope (Carl Zeiss, Oberkochen, Germany).

This analysis was performed by a single examiner blinded to the treatment performed (E.F.M). The entire trephined area was evaluated using the ImageJ image analysis program (National Institute of Health, Maryland, USA), and bone tissue areas were quantified as described by previous studies $[14,28,29]$, measuring the areas occupied by newly formed bones in $\mu \mathrm{m}^{2}$ (Figure 2).

2.9. Statistical Analysis. All the data were subjected to descriptive and exploratory analyses. Scintigraphic measurement data were subjected to the two-way analysis of variance post-Student-Newman-Keuls test. The data on newly formed bone tissue area and percentage did not meet the normality assumptions and were analyzed with the Wilcoxon paired test. A significance level of $5 \%$ was considered in all analyses.

\section{Results}

3.1. Bone Scintigraphy. The scintigraphic results of the groups evaluated are given in Table 1 . There was a higher mean amount of pixels in G2 compared to G1 $(p<0.05)$ at both times evaluated. 
TABLE 1: Mean scintigraphic analysis of the groups evaluated at the different analysis times, in pixels.

\begin{tabular}{lrr}
\hline & G1 & G2 \\
\hline 7 days & $28239.00(43.26)^{\mathrm{B}, \mathrm{b}}$ & $30833.00(106.71)^{\mathrm{A}, \mathrm{b}}$ \\
14 days & $29483.67(92.96)^{\mathrm{B}, \mathrm{a}}$ & $31781.33(127.93)^{\mathrm{A}, \mathrm{a}}$ \\
\hline
\end{tabular}

Different capital letters represent differences between groups at each time (horizontal). Different lowercase letters represent differences between times in each group (vertical). Significance level 5\%. Group 1 (G1), xenograft associated with peripheral blood; Group 2 (G2), xenograft associated with mandibular bone marrow blood aspirate.

3.2. Histological and Histomorphometric Analyses. Histological and histomorphometric results are given in Table 2 and Figure 3. The percentage of bone tissue in the analyzed region was higher in G2 (47.09 (1.11)\%) than in G1 (34.93 (1.60)\%) $(p<0.05)$.

Representative histological images of the groups are shown in Figure 2. G2 presents a greater amount of newly formed bone tissue intermingled with particles of bone substitute compared to G1.

\section{Discussion}

The treatment of partial and total edentulous patients with dental implants has become a routine treatment modality in contemporary dental practice. However, tooth loss is often associated with bone loss, with insufficient bone dimensions for not only surgical installation of the implant but also for future prosthetic rehabilitation to place the dental implant in a prosthetically optimal position $[30,31]$.

In this context, bone grafting procedures play an important role in bone tissue recovery for implant placement. Among the options for bone grafting, autologous bone blocks are still considered the gold standard, especially in regions with critical bone defects. Due to its physical and biological constitution, autologous grafts present low association with immunological reactions, in addition to having the necessary pillars for balanced bone neoformation, such as osteoconduction, osteoinduction, and osteogenesis $[32,33]$. However, studies seek the perfect biomaterial to replace this grafting format to minimize critical autogenous grafting problems, such as more than one surgical site, and limited amount of material [33].

Combined with the type of bone substitute, techniques that aim to strengthen the osteogenic potential of the biomaterial, especially by increasing its cellularity, have been a strategy to accelerate bone tissue formation, thus reducing the time to rehabilitate the patient $[14,19,34,35]$.

Thus, the objective of the present study was to evaluate the capacity of mandibular bone marrow blood aspirate associated with biomaterials to stimulate bone tissue neoformation compared to the use of peripheral blood aspirate in patients with bone loss in the premaxillary region. The clinical results showed that the association of bone marrow blood and the biomaterial increased osteogenic capacity and bone neoformation compared to peripheral blood.

Some studies show that bone marrow represents a promising source of autologous cells [5], improving its osteogenic potential $[18,36,37]$ and providing a high concentration of growth factors [38-40], which are important to form a microenvironment to stimulate mineralized bone matrix formation.

Bone marrow blood is commonly collected from the iliac crest bone [41]. However, collection from this region requires a hospital environment, being a more invasive procedure for the patient with higher costs, risk of failure in the donor region, in addition to result in difficult preambulation [42]. Thus, in an attempt to obtain bone marrow blood in an easier way, in the clinical environment, at the same surgical time, and without risk to the patient, this study evaluated the osteogenic potential of the biomaterial soaked in bone marrow blood obtained from the mandibular region compared to peripheral blood present in the surgical bed.

It is important to note that the mandible was the bone of choice for obtaining bone marrow blood, as research has shown the greater osteogenic potential of cells from this region compared to those generally obtained from long bones $[17,43-45]$, in addition to greater periosteal cell viability $[46,47]$. Viable vascularized and well-perfused bone graft is a prerequisite for graft survival; however, there is little evidence that graft viability is related to a successful clinical outcome [21, 48, 49]. Radioisotope bone scintigraphy has been proven to be an effective method to evaluate vascular patency and bone viability, especially in orthopedic surgeries $[50,51]$. In the present study, scintigraphic results showed a higher mean number of pixels with the association of bone substitute with mandibular bone marrow blood aspirate compared to peripheral blood $(p<0.05)$, which reinforces greater vascularization and greater osteogenic cell activity in the initial phase of grafting $[43,52]$ due to greater radiopharmaceutical fixation and the consequent number of pixels in G2 compared to G1.

In addition to the clinical findings, the histomorphometric results obtained from biopsy analysis confirmed a greater amount of bone tissue in the group using mandibular bone marrow blood, showing a 34.93\% higher bone neoformation compared to the association of bone substitute with peripheral blood. These findings reinforce that mandibular bone marrow blood has unique properties, which differentiates it due to its osteogenic potential compared to peripheral blood $[39,45,53]$, which is conventionally used in surgery. In addition to its reparative property, it is easier to use compared to other spinal cord blood donor regions, reducing comorbidities [1] and being an interesting alternative for grafting procedures. 
TABLE 2: Histomorphometric analysis as a function of treatment.

\begin{tabular}{lcccc}
\hline Variable & \multicolumn{2}{c}{ Treatment } & G2 \\
& $\begin{array}{c}\text { Mean (standard } \\
\text { deviation) }\end{array}$ & $\begin{array}{c}\text { Median (minimum and } \\
\text { maximum value) }\end{array}$ & $\begin{array}{c}\text { Mean (standard } \\
\text { deviation) }\end{array}$ & $\begin{array}{c}\text { Median (minimum and } \\
\text { maximum value) }\end{array}$ \\
\hline $\begin{array}{l}\text { Bone tissue area } \\
\left(\mu \mathrm{m}^{2}\right)\end{array}$ & $977.13(235.33)$ & $884.50(764.00 ; 1435.00)$ & $1838.38(1004.60)$ & $1286.00(970.00 ; 3234.00)$ \\
$\%$ of bone tissue & $34.93(1.60)^{\mathrm{a}}$ & $34.88(32.91 ; 37.22)$ & $47.09(1.11)^{\mathrm{b}}$ & $46.86(45.74 ; 49.21)$ \\
\hline
\end{tabular}

Different letters represent differences between groups. Significance level 5\%. Group 1 (G1), xenograft associated with peripheral blood; Group 2 (G2), xenograft associated with mandibular bone marrow blood aspirate.

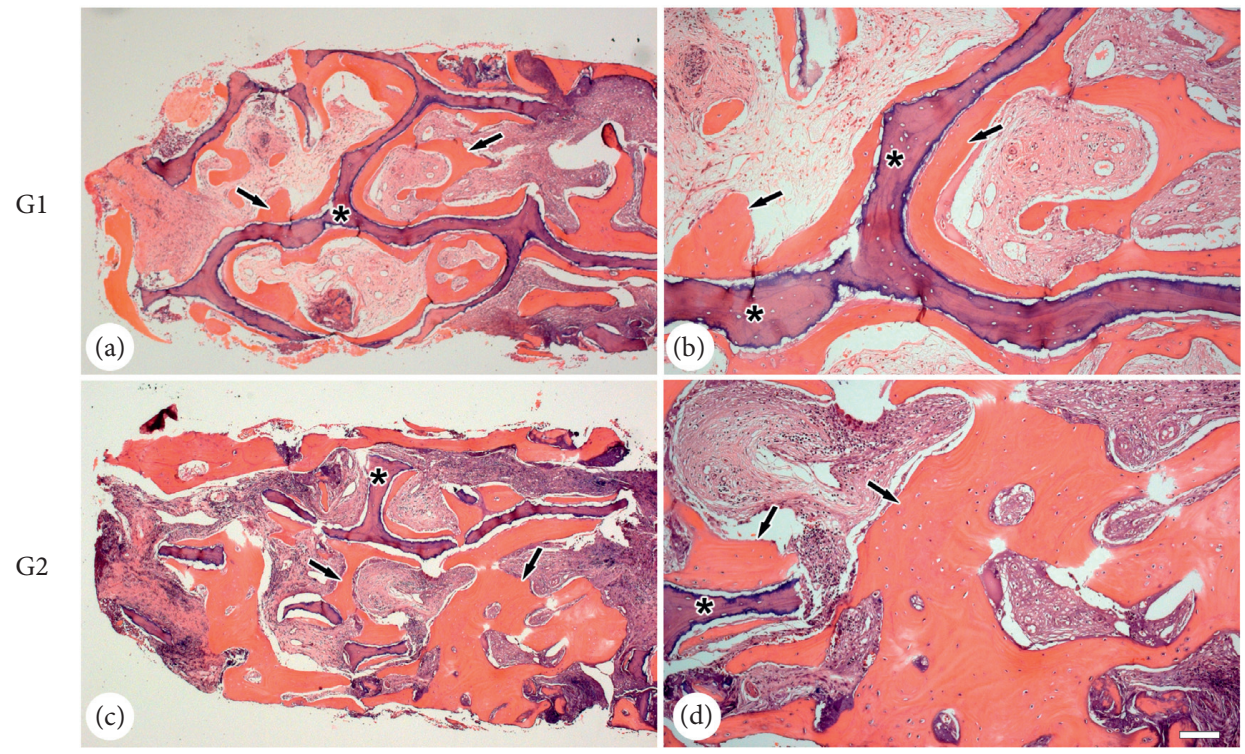

Figure 3: Histological images stained with hematoxylin and eosin from the trephined areas with different treatments. Detailed images show the presence of newly formed bone $(\longrightarrow)$ and the presence of remaining biomaterials (*). (a)-(b) Group 1 (G1), xenograft associated with peripheral blood. (c)-(d) Group 2 (G2), xenograft associated with mandibular bone marrow blood aspirate. Bars: (a) and (c)=1,000 $\mu$ m; (b) and $(\mathrm{d})=100 \mu \mathrm{m}$.

\section{Conclusions}

Appositional bone reconstruction using blocks of bone substitute associated with mandibular bone marrow blood induced greater osteogenic activity and bone neoformation than the association with peripheral blood, enabling more conservative surgical procedures.

\section{Data Availability}

The data used to support the findings of this study are available from the corresponding author upon request.

\section{Conflicts of Interest}

The authors declare that they have no conflicts of interest.

\section{Authors' Contributions}

Paulo Pasquali and Elizabeth Martinez conceptualized, investigated, and supervised the study and wrote the original draft of the article. Paulo Pasquali involved in formal analysis. Paulo Pasquali, Rodrigo Dalla'Agnol, Lucas
Rezende, and Elizabeth Martinez developed methodology, visualized the study, and wrote, reviewed, and edited the article. All authors critically revised the article.

\section{Acknowledgments}

The authors acknowledge Nancy Cristina Martorana for promptly volunteering to review this manuscript regarding its English language content and Dr. Rafael Bovi Ambrosano for helping with the statistical analysis of the data.

\section{Supplementary Materials}

Flow diagram for patient's eligibility and inclusion in the study (s). (Supplementary Materials)

\section{References}

[1] C. Camarini, G. Spagnol, M. M. Pinotti, A. M. do Canto, F. A. Maciel, and R. R. de Freitas, "Mandibular reconstruction with block iliac crest: an institutional experience," Craniomaxillofacial Trauma and Reconstruction, vol. 13, no. 4, pp. 285-289, 2020. 
[2] M. Sanz, C. Dahlin, D. Apatzidou et al., "Biomaterials and regenerative technologies used in bone regeneration in the craniomaxillofacial region: consensus report of group 2 of the 15th European Workshop on Periodontology on Bone Regeneration," Journal of Clinical Periodontology, vol. 46, pp. 82-91, 2019.

[3] F. Kawecki, W. P. Clafshenkel, M. Fortin, F. A. Auger, and J. Fradette, "Biomimetic tissue-engineered bone substitutes for maxillofacial and craniofacial repair: the potential of cell sheet technologies," Adv. Health. Mater.vol. 7, Article ID e1700919, 2017.

[4] P. Eipers, S. Kale, R. S. Taichman et al., "Bone marrow accessory cells regulate human bone precursor cell development," Experimental Hematology, vol. 28, no. 7, pp. 815-825, 2000.

[5] A. Arthur and S. Gronthos, "Clinical application of bone marrow mesenchymal stem/stromal cells to repair skeletal tissue," International Journal of Molecular Sciences, vol. 21, no. 24, Article ID 9759, 2020.

[6] D. Kaigler, P. H. Krebsbach, P. J. Polverini, and D. J. Mooney, "Role of vascular endothelial growth factor in bone marrow stromal cell modulation of endothelial cells," Tissue Engineering, vol. 9, no. 1, pp. 95-103, 2003.

[7] E. Lucarelli, M. Fini, A. Beccheroni et al., "Stromal stem cells and platelet-rich plasma improve bone allograft integration," Clinical Orthopaedics and Related Research, vol. 435, pp. 62-68, 2005.

[8] C. Frey, N. M. Halikus, T. Vu-Rose, and E. Ebramzadeh, “A review of ankle arthrodesis: predisposing factors to nonunion," Foot \& Ankle International, vol. 15, no. 11, pp. 581-584, 1994.

[9] M. E. Easley, H.-J. Trnka, L. C. Schon, and M. S. Myerson, "Isolated subtalar arthrodesis," Journal of Bone and Joint Surgery American Volume, vol. 82, no. 5, pp. 613-624, 2000.

[10] T. Schepull, J. Kvist, H. Norrman, M. Trinks, G. Berlin, and P. Aspenberg, "Autologous platelets have No effect on the healing of human achilles tendon ruptures," The American Journal of Sports Medicine, vol. 39, no. 1, pp. 38-47, 2011.

[11] M. C. Walsh, N. Takegahara, H. Kim, and Y. Choi, "Updating osteoimmunology: regulation of bone cells by innate and adaptive immunity," Nature Reviews Rheumatology, vol. 14, no. 3, pp. 146-156, 2018.

[12] S. V. Kevy and M. S. Jacobson, "Comparison of methods for point of care preparation of autologous platelet gel," Journal of Extra-Corporeal Technology, vol. 36, pp. 28-35, 2004.

[13] R. Quarto, M. Mastrogiacomo, R. Cancedda et al., "Repair of large bone defects with the use of autologous bone marrow stromal cells," New England Journal of Medicine, vol. 344, no. 5, pp. 385-386, 2001.

[14] P. J. Pasquali, M. L. Teixeira, T. A. de Oliveira, L. G. de Macedo, A. C. Aloise, and A. A. Pelegrine, "Maxillary sinus augmentation combining Bio-Oss with the bone marrow aspirate concentrate: a histomorphometric study in humans," Int. J. Biomater, vol. 121286, 2015.

[15] R. M. Lemoli, F. Bertolini, R. Cancedda et al., "Stem cell plasticity: time for a reappraisal?" Haematologica, vol. 90, pp. 360-381, 2005.

[16] S. O. Akintoye, T. Lam, S. Shi, J. Brahim, M. T. Collins, and P. G. Robey, "Skeletal site-specific characterization of orofacial and iliac crest human bone marrow stromal cells in same individuals," Bone, vol. 38, no. 6, pp. 758-768, 2006.

[17] Y. Steinhardt, H. Aslan, E. Regev et al., "Maxillofacial-derived stem cells regenerate critical mandibular bone defect," Tissue Engineering Part A, vol. 14, no. 11, pp. 1763-1773, 2008.
[18] Y. Du, F. Jiang, Y. Liang et al., "The angiogenic variation of skeletal site-specific human BMSCs from same alveolar cleft patients: a comparative study," Journal of Molecular Histology, vol. 47, no. 2, pp. 153-168, 2016.

[19] A. A. Pelegrine, A. C. Aloise, A. Zimmermann, R. de Mello e Oliveira, L. M. Ferreira, and L. M. Ferreira, "Repair of critical-size bone defects using bone marrow stromal cells: a histomorphometric study in rabbit calvaria. Part I: use of fresh bone marrow or bone marrow mononuclear fraction," Clinical Oral Implants Research, vol. 25, no. 5, pp. 567-572, 2014.

[20] S. C. Lavareda Corrêa, J. Elias de Sousa, P. J. Pasquali et al., "Use of bone allograft with or without bone marrow aspirate concentrate in appositional reconstructions: a tomographic and histomorphometric study," Implant Dentistry, vol. 26, pp. 915-921, 2017.

[21] P. Hernigou, Y. Homma, C. H. Flouzat Lachaniette et al., "Benefits of small volume and small syringe for bone marrow aspirations of mesenchymal stem cells," International Orthopaedics, vol. 37, no. 11, pp. 2279-2287, 2013.

[22] R. I. Ferreira, S. M. de Almeida, F. N. Bóscolo, A. O. Santos, and E. E. Camargo, "Bone scintigraphy as an adjunct for the diagnosis of oral diseases," Journal of Dental Education, vol. 66, no. 12, pp. 1381-1387, 2002.

[23] K. P. Droll, V. Prasad, A. Ciorau, B. G. Gray, and M. D. McKee, "The use of postoperative bone scintigraphy to predict graft retention," Canadian journal of surgery. Journal canadien de chirurgie, vol. 50, pp. 261-265, 2007.

[24] T. Krohn, A. Ghassemi, M. Gerressen, F. A. Verburg, F. M. Mottaghy, and F. F. Behrendt, "Bone graft scintigraphy," Nuklearmedizin, vol. 51, no. 05, pp. 201-204, 2012.

[25] P. Matin, "Bone scintigraphy in the diagnosis and management of traumatic injury," Seminars in Nuclear Medicine, vol. 13, no. 2, pp. 104-122, 1983.

[26] G. Buyukdereli, I. B. Guney, G. Ozerdem, and E. Kesiktas, "Evaluation of vascularized graft reconstruction of the mandible with Tc-99m MDP bone scintigraphy," Annals of Nuclear Medicine, vol. 20, no. 2, pp. 89-93, 2006.

[27] T. Niikura, S. Y. Lee, Y. Sakai, K. Nishida, R. Kuroda, and M. Kurosaka, "Comparison of radiographic appearance and bone scintigraphy in fracture nonunions," Orthopedics, vol. 37, pp. e44-50, 2014.

[28] L. C. Fontes Martins, A. L. Sousa Campos de Oliveira, A. C. Aloise et al., "Bone marrow aspirate concentrate and platelet-rich fibrin in fresh extraction sockets: a histomorphometric and immunohistochemical study in humans," Journal of Cranio-Maxillofacial Surgery, vol. 49, no. 2, pp. 104-109, 2021.

[29] A. Pelegrine, M. Teixeira, M. Sperandio et al., "Can bone marrow aspirate concentrate change the mineralization pattern of the anterior maxilla treated with xenografts? A preliminary study," Contemporary Clinical Dentistry, vol. 7, no. 1, pp. 21-26, 2016.

[30] J. H. Fu and H. L. Wang, "Horizontal bone augmentation: the decision tree," The International Journal of Periodontics \& Restorative Dentistry, vol. 31, pp. 429-436, 2011.

[31] M. S. Gowd, T. Shankar, R. Ranjan, and A. Singh, "Prosthetic consideration in implant-supported prosthesis: a review of literature," Journal of International Society of Preventive and Community Dentistry, vol. 7, pp. S1-S7, 2017.

[32] T. T. Roberts and A. J. Rosenbaum, "Bone grafts, bone substitutes and orthobiologics," Organogenesis, vol. 8, no. 4, pp. 114-124, 2012. 
[33] H. J. Haugen, S. P. Lyngstadaas, F. Rossi, and G. Perale, "Bone grafts: which is the ideal biomaterial?" Journal of Clinical Periodontology, vol. 46, pp. 92-102, 2019.

[34] L. Sununliganon, L. Peng, W. Singhatanadgit, and L. K. Cheung, "Osteogenic efficacy of bone marrow concentrate in rabbit maxillary sinus grafting," Journal of CranioMaxillofacial Surgery, vol. 42, no. 8, pp. 1753-1765, 2014.

[35] T. de Oliveira, A. Aloise, J. Orosz, R. de Mello E Oliveira, P. de Carvalho, and A. Pelegrine, "Double centrifugation versus single centrifugation of bone marrow aspirate concentrate in sinus floor elevation: a pilot study," The International Journal of Oral \& Maxillofacial Implants, vol. 31, no. 1, pp. 216-222, 2016.

[36] T. A. de Oliveira, A. C. Aloise, J. E. Orosz, R. de Mello E Oliveira, P. de Carvalho, and A. A. Pelegrine, "Similarities and differences between porcine mandibular and limb bone marrow mesenchymal stem cells," Archives of Oral Biology, vol. 77, pp. 1-11, 2017.

[37] F. Wang, Y. Zhou, J. Zhou et al., "Comparison of intraoral bone regeneration with iliac and alveolar BMSCs," Journal of Dental Research, vol. 97, no. 11, pp. 1229-1235, 2018.

[38] J. Peng, L. Chen, K. Peng et al., "Bone marrow mesenchymal stem cells and endothelial progenitor cells co-culture enhances large segment bone defect repair," Journal of Biomedical Nanotechnology, vol. 15, no. 4, pp. 742-755, 2019.

[39] J. A. Pfaff, B. Boelck, W. Bloch, and G.-H. Nentwig, "Growth factors in bone marrow blood of the mandible with application of extracorporeal shock wave therapy," Implant Dentistry, vol. 25, no. 5, pp. 606-612, 2016.

[40] T. Shoji, T. Nakasa, M. Yoshizuka et al., "Comparison of fibrin clots derived from peripheral blood and bone marrow," Connective Tissue Research, vol. 58, no. 2, pp. 208-214, 2017.

[41] P. Hernigou, A. Desroches, S. Queinnec et al., "Morbidity of graft harvesting versus bone marrow aspiration in cell regenerative therapy," International Orthopaedics, vol. 38, no. 9, pp. 1855-1860, 2014.

[42] H. C. Sagi, M. L. Young, L. Gerstenfeld, T. A. Einhorn, and P. Tornetta, "Qualitative and quantitative differences between bone graft obtained from the medullary canal (with a Reamer/ Irrigator/Aspirator) and the iliac crest of the same patient," Journal of Bone and Joint Surgery, vol. 94, no. 23, pp. 21282135, 2012.

[43] T. L. Aghaloo, T. Chaichanasakul, O. Bezouglaia et al., "Osteogenic potential of mandibular vs. long-bone marrow stromal cells," Journal of Dental Research, vol. 89, no. 11, pp. 1293-1298, 2010.

[44] I. Roato, G. Chinigò, T. Genova, L. Munaron, and F. Mussano, "Oral cavity as a source of mesenchymal stem cells useful for regenerative medicine in dentistry," Biomedicines, vol. 9, no. 9, Article ID 1085, 2021.

[45] Y. Hong, H. Xu, Y. Yang et al., "Isolation and cultivation of mandibular bone marrow mesenchymal stem cells in rats," Journal of Visualized Experiments, vol. 25, p. 162, 2020.

[46] F. Umrath, H. Steinle, M. Weber et al., "Generation of iPSCs from jaw periosteal cells using self-replicating RNA," International Journal of Molecular Sciences, vol. 20, no. 7, Article ID 1648, 2019.

[47] F. Umrath, M. Weber, S. Reinert, H.-P. Wendel, M. AvciAdali, and D. Alexander, "iPSC-derived MSCs versus originating jaw periosteal cells: comparison of resulting phenotype and stem cell potential," International Journal of Molecular Sciences, vol. 21, no. 2, Article ID 587, 2020.

[48] J. Filipowska, K. A. Tomaszewski, Ł. Niedźwiedzki, J. A. Walocha, and T. Niedźwiedzki, "The role of vasculature in bone development, regeneration and proper systemic functioning," Angiogenesis, vol. 20, no. 3, pp. 291-302, 2017.

[49] V. Wu, M. N. Helder, N. Bravenboer et al., "Bone tissue regeneration in the oral and maxillofacial region: a review on the application of stem cells and new strategies to improve vascularization," Stem Cells International, vol. 30, Article ID 6279721, 2019.

[50] J. Schuepbach, O. Dassonville, G. Poissonnet, and F. Demard, "Early postoperative bone scintigraphy in the evaluation of microvascular bone grafts in head and neck reconstruction," Head \& Face Medicine, vol. 3, no. 1, p. 20, 2007.

[51] H. Kim, K. Lee, S. Ha et al., "Predicting vascularized bone graft viability using 1-week postoperative bone SPECT/CT after maxillofacial reconstructive surgery," Nuclear Medicine and Molecular Imaging, vol. 54, no. 6, pp. 292-298, 2020.

[52] B. Lloyd, B. C. Tee, C. Headley, H. Emam, S. Mallery, and Z. Sun, "Similarities and differences between porcine mandibular and limb bone marrow mesenchymal stem cells," Archives of Oral Biology, vol. 77, pp. 1-11, 2017.

[53] T. Yamaza, G. Ren, K. Akiyama, C. Chen, Y. Shi, and S. Shi, "Mouse mandible contains distinctive mesenchymal stem cells," Journal of Dental Research, vol. 90, no. 3, pp. 317-324, 2011. 